\title{
A Single Point Mutation Converts GH84 O-GIcNAc Hydrolases into Phosphorylases: Experimental and Theoretical Evidence
}

Teze, David; Coines, Joan; Raich, Lluís; Kalichuk, Valentina; Solleux, Claude; Tellier, Charles; AndréMiral, Corinne; Svensson, Birte; Rovira, Carme

Published in:

Journal of the American Chemical Society

Link to article, DOI:

$10.1021 /$ jacs.9b09655

Publication date:

2020

Document Version

Peer reviewed version

Link back to DTU Orbit

Citation (APA):

Teze, D., Coines, J., Raich, L., Kalichuk, V., Solleux, C., Tellier, C., André-Miral, C., Svensson, B., \& Rovira, C. (2020). A Single Point Mutation Converts GH84 O-GlcNAc Hydrolases into Phosphorylases: Experimental and Theoretical Evidence. Journal of the American Chemical Society, 142(5), 2120-2124.

https://doi.org/10.1021/jacs.9b09655

\section{General rights}

Copyright and moral rights for the publications made accessible in the public portal are retained by the authors and/or other copyright owners and it is a condition of accessing publications that users recognise and abide by the legal requirements associated with these rights.

- Users may download and print one copy of any publication from the public portal for the purpose of private study or research.

- You may not further distribute the material or use it for any profit-making activity or commercial gain

- You may freely distribute the URL identifying the publication in the public portal 


\section{Communication}

\section{A single point mutation converts GH84 O-GIcNAc hydrolases into phosphorylases. Experimental and theoretical evidence.}

David Teze, Joan Coines, Lluís Raich, Valentina Kalichuk, Claude Solleux, Charles Tellier, Corinne André-Miral, Birte Svensson, and Carme Rovira

J. Am. Chem. Soc., Just Accepted Manuscript • DOI: 10.1021/jacs.9b09655 • Publication Date (Web): 09 Jan 2020

Downloaded from pubs.acs.org on January 12, 2020

\section{Just Accepted}

"Just Accepted" manuscripts have been peer-reviewed and accepted for publication. They are posted online prior to technical editing, formatting for publication and author proofing. The American Chemical Society provides "Just Accepted" as a service to the research community to expedite the dissemination of scientific material as soon as possible after acceptance. "Just Accepted" manuscripts appear in full in PDF format accompanied by an HTML abstract. "Just Accepted" manuscripts have been fully peer reviewed, but should not be considered the official version of record. They are citable by the Digital Object Identifier (DOI®). "Just Accepted" is an optional service offered to authors. Therefore, the "Just Accepted" Web site may not include all articles that will be published in the journal. After a manuscript is technically edited and formatted, it will be removed from the "Just Accepted" Web site and published as an ASAP article. Note that technical editing may introduce minor changes to the manuscript text and/or graphics which could affect content, and all legal disclaimers and ethical guidelines that apply to the journal pertain. ACS cannot be held responsible for errors or consequences arising from the use of information contained in these "Just Accepted" manuscripts. 
Glycoside hydrolases (GHs) are enzymes catalyzing the hydrolysis of glycosidic bonds. They are classified into families according to sequence similarity (http://www.cazy.org). ${ }^{1}$ Members of a given $\mathrm{GH}$ family typically share common reaction mechanism and active site architecture..$^{2-4}$ Family GH84 enzymes catalyze the cleavage of the $N$-acetylglucosamine (GlcNAc) attached to Ser/Thr residues on proteins. There is a well-established interplay between protein $O$ GlcNAcylation and phosphorylation, ${ }^{5-6}$ with $O$-GlcNAcylation modulating both protein phosphorylation and expression in essential signaling pathways. ${ }^{6}$ Animals, plants and some bacteria ${ }^{7}$ possess $O$-GlcNAc transferases and GH84 $O$-GlcNAcases (OGA) for GlcNAc cycling on selected Ser/Thr. These enzymes are thus involved in dynamic protein regulation, an unusual function for carbohydrate-active enzymes.

Given their crucial role in biology, GH84 enzymes have been extensively studied. ${ }^{8-12}$ They follow a mechanism that has been described as substrate-assisted or neighbouring group participation, ${ }^{12-14}$ which is operated by two consecutive Asp residues (Figure 1a). In the first reaction step, D119 takes a proton from the substrate $N$-acetamido group (NAc), while the oxygen atom of NAc attacks the anomeric carbon to form an oxazoline (Glc-ox) reaction intermediate. ${ }^{11}$ D120 acts as a general acid/base, assisting leaving group departure by protonating the glycosidic bond oxygen. ${ }^{8-12}$ In the second step, a water molecule, activated by the general acid/base residue, attacks on the anomeric carbon to release the product, GlcNAc.

\begin{abstract}
Glycoside hydrolases and phosphorylases are two bonds. Here we show that two GH84 O-GlcNAcase enzymes can be converted to efficient phosphorylases by a single point mutation.
Noteworthy, the mutated enzymes are over ten-fold more active than naturally occurring glucosaminide phosphorylases. We rationalize this novel transformation using molecular dynamics and
QM/MM metadynamics methods, showing that the mutation changes the electrostatic potential at the active site and reduces the energy barrier for phosphorolysis by $10 \mathrm{kcal} \cdot \mathrm{mol}^{-1}$. In addition, the
simulations unambiguously reveal the nature of the intermediate as a glucose oxazolinium ion, clarifying the debate on the nature of such reaction intermediate in glycoside hydrolases operating via substrate-assisted catalysis.
\end{abstract}
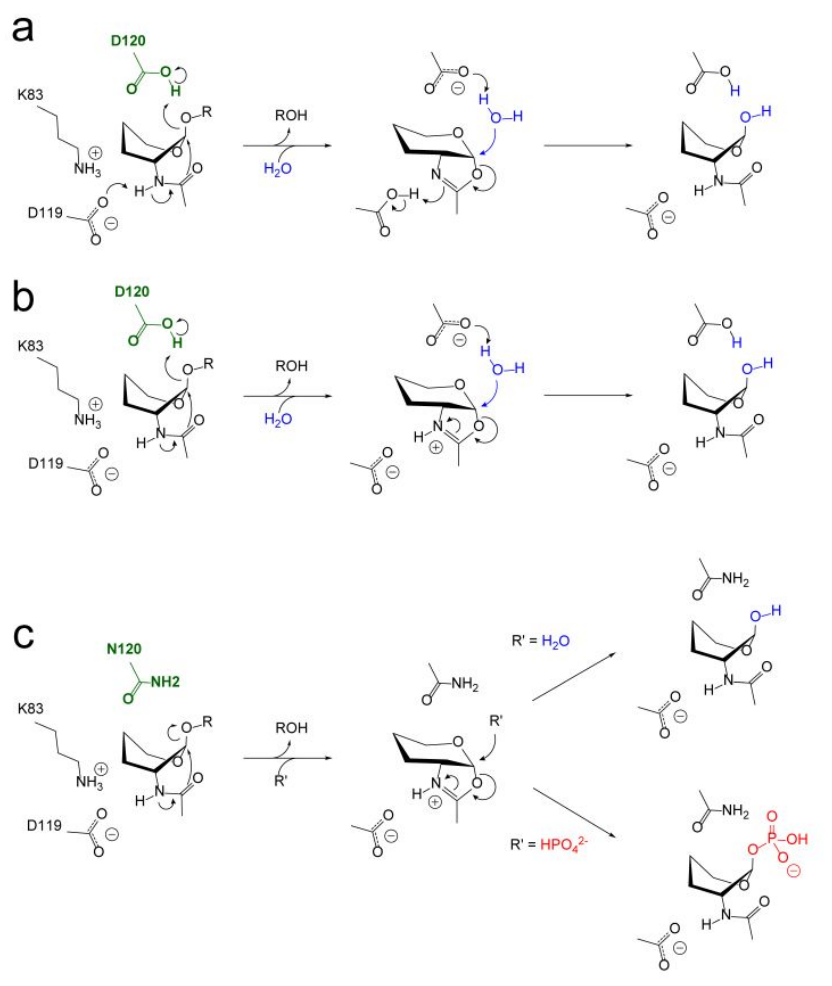

Figure 1. (a) Substrate-assisted mechanism in GH84 (TtOGA numbering). (b) The same mechanism considering an oxazolinium ion intermediate. (c) Hydrolysis and phosphorylation reactions catalyzed by $S p$ OGA-D245N and $T t$ OGA-D $120 \mathrm{~N}$.

Glycoside phosphorylases (GPs) catalyze the transfer of an inorganic phosphate to a glycoside acceptor, producing energetically valuable compounds. From mechanistic and structural standpoints, most GPs are similar to hydrolytic GHs. ${ }^{15}$ Notably, GPs are found to mingle with glycosyltransferases (families GT4 and 35) and GHs (families GH3, 13, 65, 94, 112, $130,149)^{16-17}$ rather than forming separate families. The retaining $\beta$-GPs reported to date are either $\beta-N$-acetylglucosaminide phosphorylases $^{18}$ or $\beta$-glucoside phosphorylase, ${ }^{19}$ both of which belong to family $\mathrm{GH} 3$ and catalyze phosphorolysis through a glycosyl-enzyme intermediate. ${ }^{18}$ Whereas conversion of hydrolytic 
GHs into synthetic enzymes is well stablished, ${ }^{20-21}$ including for GHs performing substrate-assisted catalysis, ${ }^{22-23}$ there is so far no report of the conversion of a genuine hydrolytic GH into a GP. Here we report such transformation for two different GHs from family GH84.

Interestingly, hydrolases and phosphorylases from GH3 display similar active sites but for their acid/base catalyst (Glu in hydrolases, His in some phosphorylases), ${ }^{18-19,24}$ suggesting that this position might determine enzyme specificity. This prompted us to mutate the acid/base catalytic residue (D245) in SpOGA, a bacterial GH84 from Streptococcus pyogenes. However, the D245H mutation led to an enzyme with no phosphorolytic activity, and severely reduced hydrolysis in $0.1 \mathrm{M}$ phosphate buffer $\mathrm{pH} 7.8$ ( $k_{\text {cat }}$ $<10^{-3} \mathrm{~s}^{-1}$ for $p$ NP-GlcNAc cleavage). Conversely, replacement of D245 by Asn led to an enzyme with an unusually high catalytic rate for a catalytic mutant $\left(k_{\text {cat }}=2.7 \pm 0.2 \mathrm{~s}^{-1}\right)$. Whereas the wild-type enzyme released exclusively GlcNAc, thin layer chromatography and capillary electrophoresis (CE) indicated the formation of a more polar compound by the SpOGA-D245N mutant in phosphate buffer. This product was absent for the catalyzed reactions occurring in HEPES or Tris buffer, with only GlcNAc release (Figure S1). $\beta$-GlcNAc-1-phosphate (GlcNAc-1-P) was identified by ${ }^{1} \mathrm{H}$ NMR as the predominant product of the action of $\mathrm{SpOGA-}$ D245N on $p$ NP-GlcNAc in $50 \mathrm{mM}$ phosphate buffer (Figure 2). At 30 and $100 \mathrm{mM}$, GlcNAc-1-P represented $55 \%$ and $76 \%$ of the final mixture, respectively (Figures S3 and S4). At $0.5 \mathrm{M}$ phosphate, GlcNAc formation was not observed by CE, and only GlcNAc-1-P was produced by $S p O G A-D 245 \mathrm{~N}$ (Figure $2 \mathrm{~b}$ ). Therefore, the D245N mutation changed enzyme activity from hydrolysis to phosphorolysis.

It is common that GHs with a mutated catalytic residue can partially recover their activity upon addition of an exogenous nucleophile. ${ }^{25}$ However, phosphate has never been described to act as such, despite being a common buffer component in enzyme reaction mixtures ${ }^{18}$ and an intrinsically better nucleophile than water. ${ }^{26}$ Addition of $0.1 \mathrm{M}$ acetate (the most common anion used for chemical rescue) to a HEPES buffer $\mathrm{pH} 7.8$ did not enhance $p$ NP-GlcNAc consumption by SpOGA-D245N. Interestingly, the substrate-assisted mechanism in $S p$ OGA-D245N is preserved despite the modification of the catalytic residue. Indeed, $\mathrm{SpOGA-}$ $\mathrm{D} 245 \mathrm{~N}$ was also able to form GlcNAc-1-P from the reaction intermediate, 2-methyl-(1,2-dideoxy- $\alpha$-D-glucopyrano)[2,1-d]$\Delta 2^{\prime}$-oxazoline (Glc-ox), and hydrolyze the formed GlcNAc-1-P (Figure S5). Moreover, it catalyzed phosphorylation of both Glcox and $p$ NP-GlcNAc at the same rate (Figure S5). Together with the rate enhancement observed upon phosphate addition (Figures S6 and S7, also showing no phosphate saturation for SpOGAD245N phosphorolysis), this indicates that phosphorylation of Glcox is rate-limiting. Therefore, the $\mathrm{D} 245 \mathrm{~N}$ mutation creates a retaining glycoside phosphorylase (GP) that catalyzes phosphorolysis through a substrate-assisted mechanism (Figure 1c). To the best of our knowledge, this is the first example of a conversion of a GH into a GP by mutagenesis. a

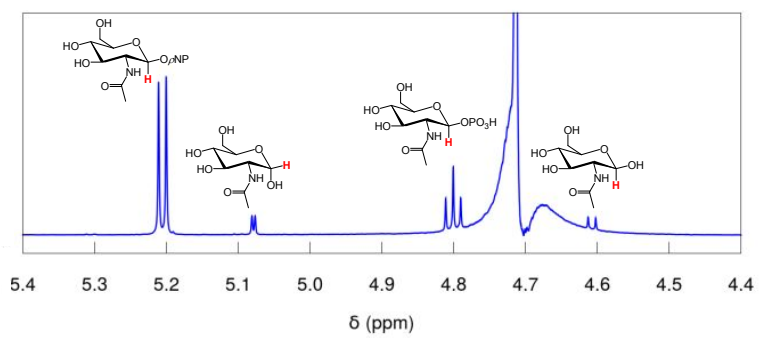

b

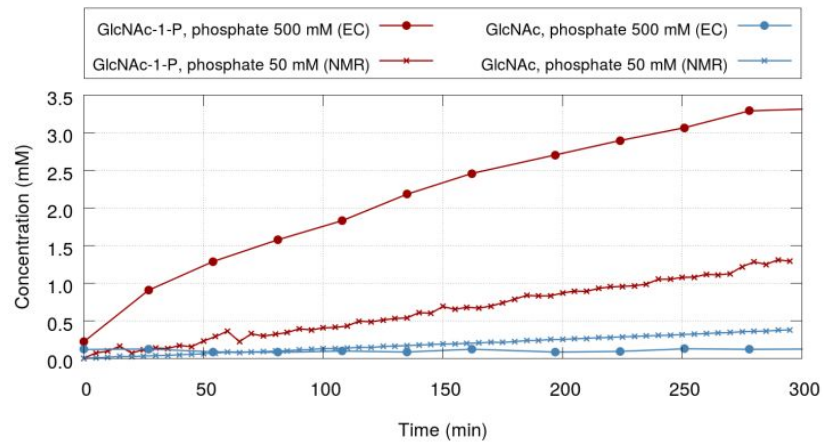

Figure 2. (a) NMR spectrum of phosphorolysis and hydrolysis of $7.5 \mathrm{mM} p$ NPGlcNAc by $1 \mu \mathrm{g} \cdot \mathrm{mL}^{-1} S p$ OGA-D245N in $50 \mathrm{mM}$ phosphate $\mathrm{pH} 7.8$, after $180 \mathrm{~min}$. (b) Time course of phosphorolysis and hydrolysis of $7.5 \mathrm{mM} p$ NPGlcNAc by 1 $\mu \mathrm{g} \cdot \mathrm{mL}^{-1} S p$ OGA-D245N in 50 or $500 \mathrm{mM}$ phosphate $\mathrm{pH} 7.8$, monitored by NMR or CE.

Strikingly, the observed catalytic constant of $S p$ OGA-D245N towards $p$ NP-GlcNAc in presence of $0.1 \mathrm{M}$ phosphate $\left(k_{\text {cat }}=2.7 \mathrm{~s}^{-}\right.$ $\left.{ }^{1}\right)$ is higher than those reported for the natural $\beta$-GlcNAc phosphorylases Nag3 and BglP of family GH3 $\left(k_{\text {cat }}[\mathrm{Nag} 3]=0.15\right.$ $\left.\mathrm{s}^{-1} ; k_{\text {cat }}[\mathrm{BglP}]=0.03 \mathrm{~s}^{-1}\right) \cdot{ }^{18-19} S p$ OGA-D245N is thus an efficient catalyst superior to the reported natural GPs for the synthesis of GlcNAc-1-P.

The molecular determinants of catalysis of the first substrateassisted phosphorylase, SpOGA-D245N, were uncovered by means of computer simulation. As no crystal structure is available for $S p$ OGA, we examined its closest structurally determined analogue, TtOGA from Thermobaculum terrenum, ${ }^{7}$ which shares $33 \%$ sequence identity with SpOGA. NMR spectroscopy and anion-exchange chromatography product analysis showed that its general acid/base mutant TtOGA-D120N was also able to catalyze phosphorolysis, while wild-type $T t$ OGA (TtOGA-WT) was a genuine hydrolase (Figures S2 and S8). TtOGA-D120N presented a $41 \%$ rate enhancement of $p$ NP release observed upon addition of $20 \mathrm{mM}$ phosphate into $50 \mathrm{mM}$ HEPES buffer $\mathrm{pH} 7.8\left(k_{\text {cat }}=4.4 \pm 0.2\right.$ $\left.\mathrm{s}^{-1} ; K_{\mathrm{M}}=16 \pm 1.3 \mu \mathrm{M}\right)$, catalyzing both phosphorolysis $(30 \%)$ and hydrolysis (70\%) (Figure S8). Hydrolysis was predominant at higher phosphate concentrations as well.

The structure of TtOGA-D120N in complex with GlcNAc (pdb 5DIY) solved at $2.06 \AA$ resolution ${ }^{7}$ was taken as initial structure for the simulations. To reconstruct the reaction intermediate, molecular dynamics (MD) simulations were performed after replacing the active site GlcNAc by a glucose oxazolinium ion $\left(\mathrm{Glc}-\mathrm{ox}^{+}\right)$for both $T t$ OGA-D120N and TtOGA-WT (Figures $\mathrm{S} 9$ and $\mathrm{S} 10$ ). $\mathrm{H}_{2} \mathrm{PO}_{4}^{-} / \mathrm{HPO}_{4}{ }^{2-}$ anions were used to model a phosphate concentration of $20 \mathrm{mM}$ at $\mathrm{pH}$ 7.8. The MD simulations showed that phosphate anions do not reach the active site of TtOGA-WT (Figure 3a), due to electrostatic repulsion from the D120 carboxylate, as reflected in the enzyme electrostatic potential at the active site (Figure 3a). However, the more positive $T t$ OGA-D120N active site displays $\mathrm{H}_{2} \mathrm{PO}_{4}{ }^{-} / \mathrm{HPO}_{4}{ }^{2-}$ anions within $\approx 3 \AA$ of the anomeric carbon, in a favorable position for nucleophilic attack. 
The mechanisms of hydrolysis and phosphorylation in $T t$ OGA-WT were modelled by QM(DFT)/MM metadynamics. ${ }^{27-28}$ This methodology has successfully been used to model catalysis in carbohydrate-active enzymes. ${ }^{29-32}$ First of all, we evaluated the reactivity of the Glc-oxazoline/oxazolinium ion intermediate in $T t$ OGA-WT, using two collective variables (CVs, see definition in Figure S11). One collective variable (CV1) takes into account the nucleophilic attack on $\mathrm{C} 1$ (from either water or $\mathrm{HPO}_{4}{ }^{2-}$ ), while the other one (CV2) assesses the proton transfer from the protonated nucleophile (water or phosphate anion) to the acid/base catalytic residue. The hydrolysis reaction was found to be exergonic and dissociative (the $\mathrm{C} 1-\mathrm{O}_{\mathrm{x}}$ bond is already broken at the oxocarbenium ion-like TS; Supplementary Table S4). The computed reaction free energy barrier $\left(13.2 \mathrm{kcal} \cdot \mathrm{mol}^{-1}\right)$ is in good agreement with experiments $\left(k_{\text {cat }}=106 \mathrm{~s}^{-1} ; \Delta G^{t}=14.7 \mathrm{kcal} \cdot \mathrm{mol}^{-1}\right)$.

To model the phosphorylation reaction in TtOGA-WT, and given the absence of phosphate molecules close to the anomeric carbon, we manually placed a $\mathrm{H}_{2} \mathrm{PO}_{4}{ }^{-}$anion in the active site and performed QM/MM metadynamics simulations. However, phosphorylation resulted in a high energy barrier $\left(26.3 \mathrm{kcal} \cdot \mathrm{mol}^{-1}\right.$, Figure $\left.3 \mathrm{~b}\right)$ and the reaction turned out to be endergonic, thus the reaction appears to be unfavorable both kinetically and thermodynamically. This indicates that would a phosphate ion visit the active site, which does not happen according to our classical MD simulation, it would not react. This is consistent with the lack of phosphorolytic activity for the TtOGA-WT.

The same methodology was used to understand the phosphorolysis reaction catalyzed by $T t \mathrm{OGA}-\mathrm{D} 120 \mathrm{~N}$. In this case, phosphate ions were found to be stable near the Glcoxazoline/oxazolinium ion during the classical MD simulations (Figure 3a). The QM/MM reaction free energy landscape (Figure 3b) reveals that, in contrast to the simulations for TtOGA-WT, phosphorylation is exergonic, with a low reaction free energy barrier $\left(14.8 \mathrm{kcal} \cdot \mathrm{mol}^{-1}\right)$ that is in good agreement with experiments $\left(k_{\mathrm{cat}}=4.4 \mathrm{~s}^{-1} ; \Delta G^{t}=16.3 \mathrm{kcal} \cdot \mathrm{mol}^{-1}\right)$. Therefore, both experiments and simulations evidence that $T t \mathrm{OGA}-\mathrm{D} 120 \mathrm{~N}$ is an efficient $\beta$-GlcNAc phosphorylase, with an activity comparable to the hydrolytic one from TtOGA-WT $\left(k_{\mathrm{cat}}=106 \mathrm{~s}^{-1}\right)$.

Analysis of the atomic rearrangements during the phosphorylation reaction (Figures S12 and S14) reveals distinct changes in active site interactions upon the D120N substitution. In $T t$ OGA-WT, the carboxylate of the acid/base catalyst (D120) interacts with the phenolic hydroxyls of both Y14 and Y168 (Figure S14). However, the corresponding residue in the mutated enzyme (N120) does not interact with Y14 but with Y168 and the nucleophilic oxygen atom $\left(\mathrm{O}_{\mathrm{P}}\right)$ of the $\mathrm{HPO}_{4}{ }^{2-}$ (Figure S14), which in turn interacts with Y14 (Figure 3c). These small structural changes, together with the changes in electrostatic potential of the active site upon the mutation, keep the incoming $\mathrm{HPO}_{4}{ }^{2-}$ ion above the substrate anomeric carbon in a reactive configuration, hence enabling phosphorylation. a

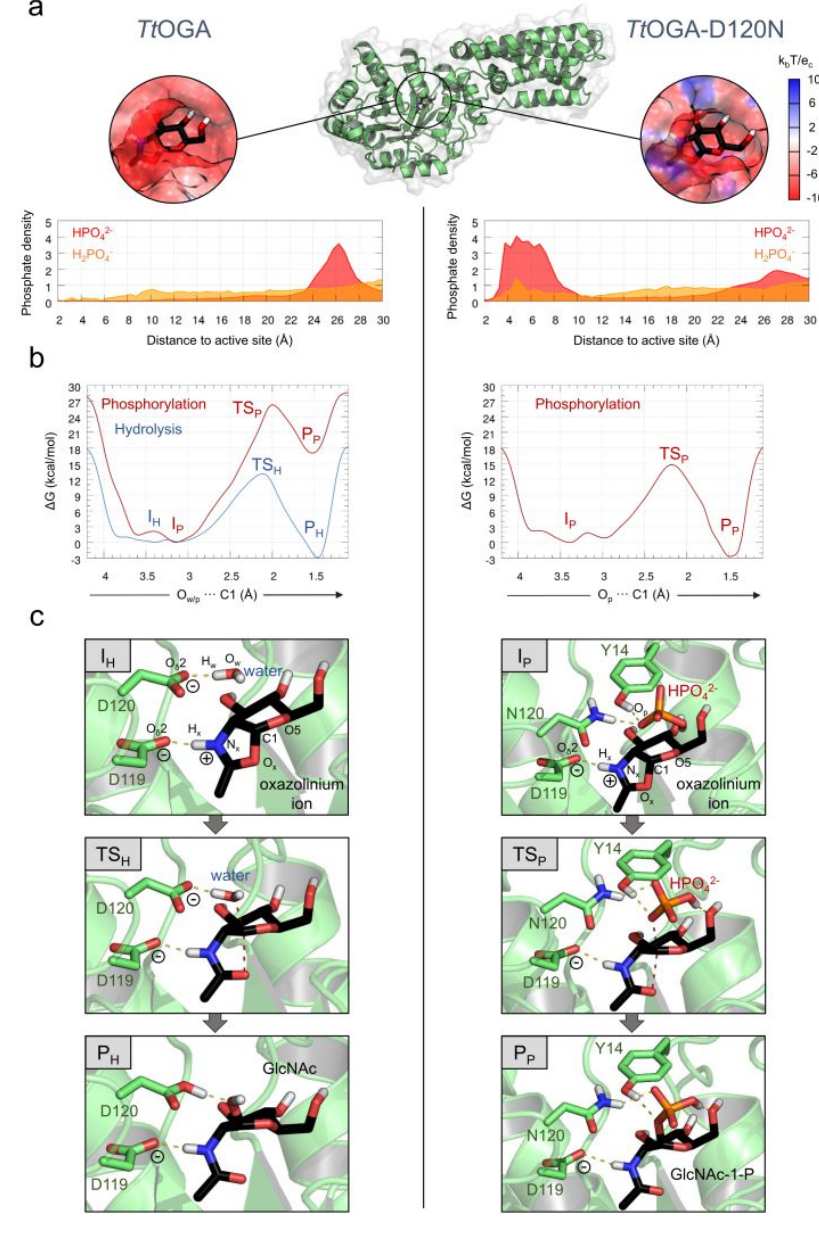

Figure 3. (a) Computed electrostatic potential of the enzyme at the active site and radial distribution function of the distance between the $C \gamma$ of the D120/N120 residue and the closest oxygen of each phosphate ion. (b) Free energy profile reconstructed from the metadynamics simulation for $T t$ OGA (left) and TtOGA-D120N (right). (c) Representative structures along the reaction coordinate for TtOGA hydrolysis (left) and TtOGA-D120N phosphorolysis (right). Bonds being formed/broken are indicated with red dashed lines.

GH84s share some relatedness with GH25, 56 and 123, as well as with GH-K clan members (GH18, 20 and 85). ${ }^{33-34}$ These enzymes also catalyze hydrolysis via substrate-assisted mechanisms, and exhibit either a Cat-Cat (GH20, 84 and 123, here D119-D120 for TtOGA) or a Cat-X-Cat (GH18, 25, 56, 85) sequential organization of their catalytic residues (Cat). A debated issue in these enzymes is the nature of the reaction intermediate, whether it is protonated (glucose oxazolinium ion, Glc-ox ${ }^{+}$) or unprotonated (Glc-ox). ${ }^{35}$ It has been theoretically demonstrated that the intermediate is unprotonated (neutral oxazoline; Figure 1a) for GH18 chitinases. ${ }^{35}$ All our simulations for native or mutated $O$ GlcNAcase GH84 (Figures 3 and S15) are consistent with an oxazolinium ion intermediate. In the chitinases case, the Cat-X-Cat organization allows the two catalytic residues to always share a proton, ${ }^{35}$ leading to a hydrogen bond network that increases the $\mathrm{p} K_{\mathrm{a}}$ of the assisting Cat residue. This scenario cannot take place in GH84 due to its two catalytic residues being consecutive (Cat-Cat). Moreover, the assisting Cat residue D119 is involved in a ionic interaction with $\mathrm{K} 43$, which lowers its $\mathrm{p} K_{\mathrm{a}}$ and precludes D119 from deprotonating the Glc-ox ${ }^{+}$species (the $\mathrm{p} K_{\mathrm{a}}$ of Glc-ox ${ }^{+}$was estimated at $7.7^{36}$ ). Therefore, the architecture of the active site in 
GH84 suggests that the intermediate is protonated, as demonstrated by our QM/MM simulations. Our work also suggests that there are at least two distinct substrate-assisted mechanisms among GHs: one in which the assisting residue plays the role of an acid/base, protonating and deprotonating the NAc group, leading to an oxazoline-type intermediate (GH18); and another one in which the assisting residue acts as a stabilizing residue, forming an ionic bond with the oxazolinium ion-type intermediate (GH84).

In conclusion, we have demonstrated that hydrolytic GHs enzymes can be turned into GPs by a single-point mutation. This small modification drastically changes the electrostatic potential of the active site, allowing the highly charged $\mathrm{HPO}_{4}{ }^{2-}$ to accommodate and react. We also provide evidence that the intermediate of GH84-catalyzed reactions is a protonated oxazolinium ion. These insights expand our understanding both of GHs following a substrate-assisted mechanism, and of what distinguishes glycoside hydrolases from glycoside phosphorylases, providing a basis for the generation of enzymatic variants that could be amenable for the production of valuable phosphorylated glycosides.

\section{ASSOCIATED CONTENT}

\section{Supporting Information}

Experimental methods and computational details. The Supporting Information is available free of charge on the ACS Publications website.

\section{AUTHOR INFORMATION}

\section{Corresponding Author}

David Teze (datez@dtu.dk)

Birte Svensson (bis@bio.dtu.dk)

Carme Rovira (c.rovira@ub.edu)

\section{Present Addresses}

†Freie Universität Berlin, Arnimallee 6, 14195 Berlin, Germany.

\section{Author Contributions}

$¥$ These authors contributed equally.

\section{Notes}

The authors declare no competing financial interests.

\section{ACKNOWLEDGMENT}

This work was supported by grants from MICINN (CTQ201785496-P, FEDER, MDM-2017-0767 to C.R.), AGAUR (2017SGR-1189 to CR), DFF, DFT, the Carlsberg Foundation (to B.S.), the Villum Foundation (DTU NMR center), NNF (NNF17OC0025660 to D.T.). We are grateful to D.M.F. Van Aalten and A. Ferenbach for providing a plasmid encoding the TtOGA gene. J.C. thanks MINECO for a predoctoral fellowship (FPI-BES-2015-072055). The authors acknowledge the computer resources at MareNostrum and Minotauro and the technical support provided by BSC-CNS (QSB-2019-3-0001).

\section{REFERENCES}

1. Lombard, V.; Golaconda Ramulu, H.; Drula, E.; Coutinho, P. M.; Henrissat, B., The carbohydrate-active enzymes database (CAZy) in 2013. Nucleic Acids Res. 2014, 42 (Database issue), D490-5.
2. Speciale, G.; Thompson, A. J.; Davies, G. J.; Williams, S. J., Dissecting conformational contributions to glycosidase catalysis and inhibition. Curr. Opin. Struct. Biol. 2014, 28C, 1-13.

3. Rye, C. S.; Withers, S. G., Glycosidase mechanisms. Curr. Opin. Chem. Biol. 2000, 4 (5), 573-80.

4. Davies, G. J.; Planas, A.; Rovira, C., Conformational analyses of the reaction coordinate of glycosidases. Acc. Chem. Res. 2012, 45 (2), $308-16$.

5. Trapannone, R.; Rafie, K.; van Aalten, D. M., O-GlcNAc transferase inhibitors: current tools and future challenges. Biochem. Soc. Trans. 2016, 44 (1), 88-93.

6. Hart, G. W.; Housley, M. P.; Slawson, C., Cycling of O-linked beta-N-acetylglucosamine on nucleocytoplasmic proteins. Nature 2007, 446 (7139), 1017-22.

7. Ostrowski, A.; Gundogdu, M.; Ferenbach, A. T.; Lebedev, A. A.; van Aalten, D. M., Evidence for a Functional O-Linked NAcetylglucosamine (O-GlcNAc) System in the Thermophilic Bacterium Thermobaculum terrenum. J. Biol. Chem. 2015, 290 (51), 30291-305.

8. Vocadlo, D. J., O-GlcNAc processing enzymes: catalytic mechanisms, substrate specificity, and enzyme regulation. Curr. Opin. Chem. Biol. 2012, 16 (5-6), 488-97.

9. $\quad$ Cetinbas, N.; Macauley, M. S.; Stubbs, K. A.; Drapala, R.; Vocadlo, D. J., Identification of Asp174 and Asp175 as the key catalytic residues of human O-GlcNAcase by functional analysis of site-directed mutants. Biochemistry 2006, 45 (11), 3835-44.

10. Yuzwa, S. A.; Shan, X.; Macauley, M. S.; Clark, T. Skorobogatko, Y.; Vosseller, K.; Vocadlo, D. J., Increasing O-GlcNAc slows neurodegeneration and stabilizes tau against aggregation. Nat. Chem. Biol. 2012, 8 (4), 393-9.

11. Cekic, N.; Heinonen, J. E.; Stubbs, K. A.; Roth, C.; He, Y.; Bennet, A. J.; McEachern, E. J.; Davies, G. J.; Vocadlo, D. J., Analysis of transition state mimicry by tight binding aminothiazoline inhibitors provides insight into catalysis by human O-GlcNAcase. Chem. Sci. 2016, 7 (6), 3742-3750.

12. He, Y.; Macauley, M. S.; Stubbs, K. A.; Vocadlo, D. J.; Davies, G. J., Visualizing the reaction coordinate of an O-GlcNAc hydrolase. $J$. Am. Chem. Soc. 2010, 132 (6), 1807-9.

13. Li, B.; Li, H.; Lu, L.; Jiang, J., Structures of human OGlcNAcase and its complexes reveal a new substrate recognition mode. Nat. Struct. Mol. Biol. 2017, 24 (4), 362-369.

14. Macauley, M. S.; Whitworth, G. E.; Debowski, A. W.; Chin, D.; Vocadlo, D. J., O-GlcNAcase uses substrate-assisted catalysis: kinetic analysis and development of highly selective mechanism-inspired inhibitors. J. Biol. Chem. 2005, 280 (27), 25313-22.

15. Puchart, V., Glycoside phosphorylases: structure, catalytic properties and biotechnological potential. Biotechnol. Adv. 2015, 33 (2), 261-76.

16. Kitaoka, M., Diversity of phosphorylases in glycoside hydrolase families. Applied microbiology and biotechnology 2015, 99 (20), 8377 90.

17. Macdonald, S. S.; Armstrong, Z.; Morgan-Lang, C.; Osowiecka, M.; Robinson, K.; Hallam, S. J.; Withers, S. G., Development and Application of a High-Throughput Functional Metagenomic Screen for Glycoside Phosphorylases. Cell Chem. Biol. 2019, 26 (7), 1001-1012 e5. 18. Macdonald, S. S.; Blaukopf, M.; Withers, S. G., Nacetylglucosaminidases from CAZy family $\mathrm{GH} 3$ are really glycoside phosphorylases, thereby explaining their use of histidine as an acid/base catalyst in place of glutamic acid. J. Biol. Chem. 2015, 290 (8), 4887-95. 19. Macdonald, S. S.; Patel, A.; Larmour, V. L. C.; Morgan-Lang, C.; Hallam, S. J.; Mark, B. L.; Withers, S. G., Structural and mechanistic analysis of a beta-glycoside phosphorylase identified by screening a metagenomic library. J. Biol. Chem. 2018, 293 (9), 3451-3467.

20. Mackenzie, L. F.; Wang, Q.; Warren, R. A. J.; Withers, S. G., Glycosynthases: Mutant Glycosidases for Oligosaccharide Synthesis. $J$. Am. Chem. Soc. 1998, 120 (22), 5583-5584.

21. Malet, C.; Planas, A., From beta-glucanase to betaglucansynthase: glycosyl transfer to alpha-glycosyl fluorides catalyzed by a mutant endoglucanase lacking its catalytic nucleophile. FEBS Lett 1998, 440 (1-2), 208-12.

22. Fairbanks, A. J., The ENGases: versatile biocatalysts for the production of homogeneous N-linked glycopeptides and glycoproteins. Chem. Soc. Rev. 2017, 46 (16), 5128-5146.

23. Kobayashi, S.; Kiyosada, T.; Shoda, S.-i., Synthesis of Artificial Chitin: Irreversible Catalytic Behavior of a Glycosyl Hydrolase through 
a Transition State Analogue Substrate. J. Am. Chem. Soc. 1996, 118 (51), 13113-13114.

24. Ducatti, D. R.; Carroll, M. A.; Jakeman, D. L., On the phosphorylase activity of $\mathrm{GH} 3$ enzymes: A beta-Nacetylglucosaminidase from Herbaspirillum seropedicae SmR1 and a glucosidase from Saccharopolyspora erythraea. Carbohydr. Res. 2016, $435,106-112$.

25. Viladot, J. L.; de Ramon, E.; Durany, O.; Planas, A., Probing the mechanism of Bacillus 1,3-1,4-beta-D-glucan 4-glucanohydrolases by chemical rescue of inactive mutants at catalytically essential residues. Biochemistry 1998, 37 (32), 11332-42.

26. Wells, P. R., Linear Free Energy Relationships. Chem. Rev. 1963, $63(2), 171-219$.

27. Laio, A.; Parrinello, M., Escaping free-energy minima. Proc. Natl. Acad. Sci. USA 2002, 99 (20), 12562-12566.

28. Barducci, A.; Bonomi, M.; Parrinello, M., Metadynamics. WIREs Comput. Mol. Sci. 2011, 1 (5), 826-843.

29. Ardèvol, A.; Rovira, C., Reaction mechanisms in carbohydrateactive enzymes: glycoside hydrolases and glycosyltransferases. Insights from ab initio quantum mechanics/molecular mechanics dynamic simulations. J. Am. Chem. Soc. 2015, 137 (24), 7528-47.

30. Bilyard, M. K.; Bailey, H. J.; Raich, L.; Gafitescu, M. A.; Machida, T.; Iglesias-Fernandez, J.; Lee, S. S.; Spicer, C. D.; Rovira, C.; Yue, W. W.; Davis, B. G., Palladium-mediated enzyme activation suggests multiphase initiation of glycogenesis. Nature 2018, 563 (7730), 235-240.
31. Tankrathok, A.; Iglesias-Fernández, J.; Luang, S.; Robinson, R. C.; Kimura, A.; Rovira, C.; Hrmova, M.; Ketudat Cairns, J. R., Structural analysis and insights into the glycon specificity of the rice $\mathrm{GH} 1$ Os7BGlu26 beta-D-mannosidase. Acta Crystallogr. D 2013, 69 (Pt 10), 2124-35.

32. Iglesias-Fernandez, J.; Hancock, S. M.; Lee, S. S.; Khan, M.; Kirkpatrick, J.; Oldham, N. J.; McAuley, K.; Fordham-Skelton, A.; Rovira, C.; Davis, B. G., A front-face 'SNi synthase' engineered from a retaining 'double-SN2' hydrolase. Nat. Chem. Biol. 2017, 13 (8), 874-881. 33. Naumoff, D. G., Hierarchical classification of glycoside hydrolases. Biochemistry (Mosc) 2011, 76 (6), 622-35.

34. Roth, C.; Petricevic, M.; John, A.; Goddard-Borger, E. D.; Davies, G. J.; Williams, S. J., Structural and mechanistic insights into a Bacteroides vulgatus retaining N-acetyl-beta-galactosaminidase that uses neighbouring group participation. Chem. Commun. 2016, 52 (74), 110969.

35. Coines, J.; Alfonso-Prieto, M.; Biarnes, X.; Planas, A.; Rovira, C., Oxazoline or Oxazolinium Ion? The Protonation State and Conformation of the Reaction Intermediate of Chitinase Enzymes Revisited. Chem. Eur. J. 2018, 24 (72), 19258-19265.

36. Greig, I. R.; Zahariev, F.; Withers, S. G., Elucidating the nature of the Streptomyces plicatus beta-hexosaminidase-bound intermediate using ab initio molecular dynamics simulations. J. Am. Chem. Soc. 2008, $130(51), 17620-8$. 
TOC graphic

1
2

3

4

5

6

7

8

9

10

11

12

13

14

15

16

17

18

19

20

21

22

23

24

25

26

27

28

29

30

31

32

33

34

35

36

37

38

39

40

41

42

43

44

45

46

47

48

49

50

51

52

53

54

55

56

57

58

59

60
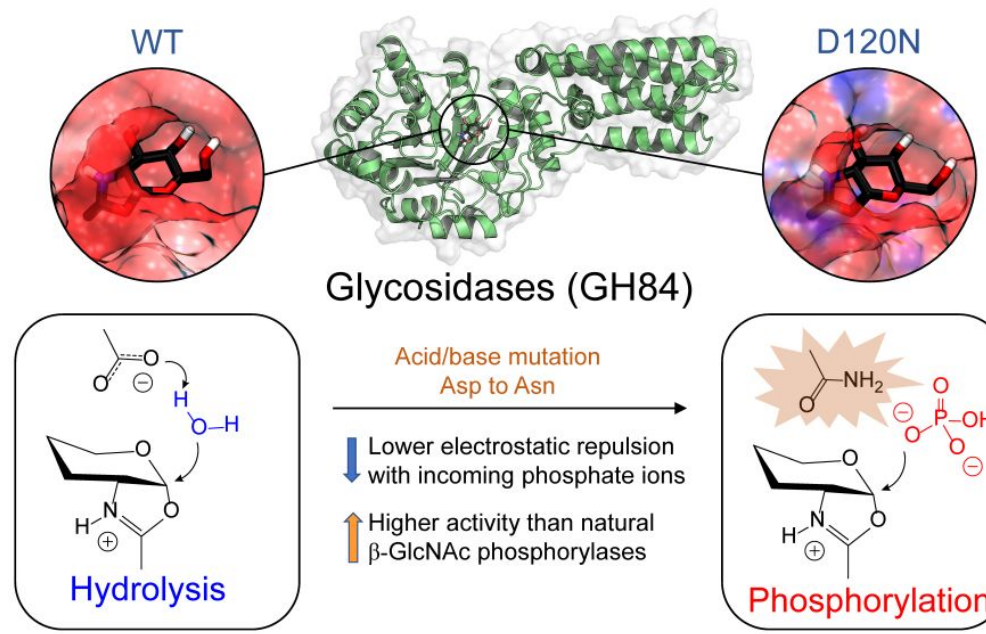

Glycosidases (GHe

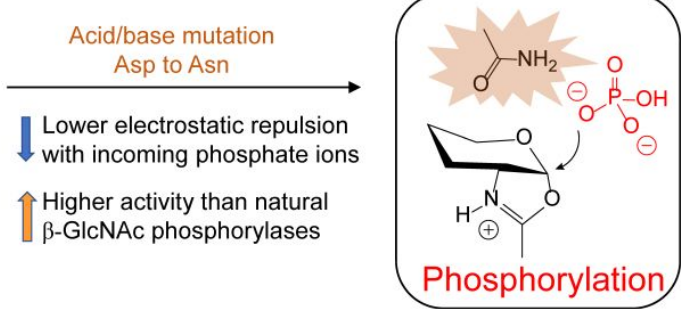

